\title{
Laudatio de El suicidio, de Durkheim
}

José Enrique Rodríguez Ibáñez

Universidad Complutense de Madrid. Facultad de Ciencias Políticas y Sociología.

Departamento de Teoría Sociológica

Campus de Somosaguas. 28023 Madrid. Spain

\section{Resumen}

El texto conmemora el centenario de la publicación de El suicidio, de Durkheim, considerándolo un hito en la teoría y la investigación sociológicas por la sencilla razón de que la fecundidad de las hipótesis y de los métodos desplegados en el clásico todavía es patente cien años más tarde.

Palabras clave: teoría sociológica, Durkheim, suicidio.

\section{Abstract}

This commentary commemorates the centennial of Durkheim's Suicide, which is depicted as a landmark in the history of sociological theory and social by virtue of the fertility that Durkheim's hypotheses and methods still possess one hundred years later.

Key words: sociological theory, Durkheim, suicide.

Pienso que una de las pocas cosas sobre la que recae consenso absoluto entre las filas de practicantes y estudiosos de la sociología es que existen dos ejemplos cumbre de hacer buena teoría y buena investigación simultáneas dentro del legado de los grandes clásicos, y que estos ejemplos señeros son El suicidio, de Durkheim, y La ética protestante y el espiritu del capitalismo, de Max Weber.

Ambos trabajos, en efecto, resumen el ideal de las ciencias sociales, que no debería ser otro que el de saber desarrollar hipótesis de trabajo sólidas, mediante metodologías solventes, para desembocar en conclusiones fiables y susceptibles de ser refutadas y contrastadas; todo ello, además, con elegancia y parsimonia, exhaustividad documental y bibliográfica y lenguaje preciso y atractivo.

En el caso de Max Weber, La ética protestante... agota hasta sus últimas consecuencias el método «comprensivo» del autor, destacando, entre otras muchas alternativas, una poderosa variable explicativa de índole cultural, cuyas repercusiones en el período de cambio de la Europa renacentista permiten al autor elaborar un modelo interpretativo alejado de fáciles determinismos y 
atento a las "conexiones de sentido" de signo macro. La teoría sociológica basada en líneas de causalidad cultural o ideológica, en grandes sistemas de significado y racionalidades colectivas de fondo alcanzaba la madurez.

Frente a Weber, Durkheim no pretende inaugurar un método históricocultural propio de la ciencia social, sino que incluye al método sociológico en la gran familia del método científico. La causalidad se tiene que basar en conexiones rigurosas que vayan del antecedente al consecuente, y de éste a sus repercusiones objetivas, a lo largo de un razonamiento que establezca la primacía de las variables y las probadas correlaciones estadísticas. Frente a la «comprensión» y la lógica cultural de Weber, la sociología de corte eminentemente explicativo y funcional se vestía de largo de la mano de Durkheim.

Esa peculiar apuesta teórica y metodológica durkheimiana es la que $\mathrm{El}$ suicidio representa excelentemente, hasta el punto de convertirse en brillante compendio de una determinada óptica sociológica — aquella que a mí me gusta denominar normativa o estructural.

Aparecida en 1897, la obra más popular de Durkheim trataba de prolongar hacia el terreno de la realidad empírica el cuerpo de convicciones que el autor había ya expuesto y defendido en Las reglas del método sociológico y la División del trabajo social, esto es, que la sociedad es una suma de hechos sociales que alcanzan la densidad coactiva y la estabilidad necesarias para poder ser tildados de "cosas» (datos, diríamos hoy); que esa suma gravita a modo de "conciencia colectiva" sobre los individuos; que las diversas sociedades constituyen redes institucionales sobre las que deben recaer los análisis comparativos; que los comportamientos regulares del homo sociologicus pueden y tienen que ser explicados con arreglo a variables pertenecientes a la sociedad en su conjunto y no a las psiques individuales o al azar.

El empeño de Durkheim fue mostrar, con las armas de la sociología en la mano, que la mayor excepción a su teoría del hecho social y la solidaridad orgánica —o sea, el suicidio, como indicador de máxima ruptura de la cohesión social por parte de individuos aislados - podía paradójicamente explicarse en virtud de las propias características de la sociedad en la que el suicidio se produce.

Para llevar adelante tal programa, el autor se esforzó, primero, en considerar el suicidio como estricto dato sociológico - y no como enfermedad o rasgo étnico o medioambiental_, para hacerlo depender, a continuación, de sesgos dominantes de la sociedad en que acontezca, desembocando en la formulación de tipologías ad hoc.

Es la machacona insistencia de Durkheim en hacer del suicidio un indicador preciso del mayor o menor grado de incidencia de unas u otras variables en el seno de una determinada sociedad lo que otorga al trabajo sus mayores virtudes, más allá de la relevancia que aún pueda poseer en el campo de la psicología clínica (la cual no es ya unilateral en sus enfoques, admitiendo vastas motivaciones para los suicidios al margen de las eminentemente sociológicas).

Me centraré, pues, en lo genuinamente sociológico de la obra en cuestión, aunque sin ignorar, por supuesto, que El suicidio, de Durkheim, según ha pues- 
to de manifiesto Castilla del Pino, sigue erigiéndose en referencia inexcusable para toda persona que trate de afrontar la muerte voluntaria y autoinfligida desde cualquier punto de vista ${ }^{1}$.

En concreto, son dos las variables explicativas del suicidio que maneja Durkheim: por un lado la integración y por otro la organización. Por integración, el autor entiende el mayor o menor grado de valores o vínculos comunitarios presentes en una sociedad. Integración es sinónimo de consenso moral y parece aludir a sociedades tradicionales. Se trataría, pues, de una variable con perfume diacrónico o histórico. A tenor de la misma, las sociedades muy integradas (por lazos religiosos, familiares, de lealtad grupal, etc.) generarían un tipo de suicidio «altruista» (el de los viudos, el de los militares vencidos, etc.), en el cual el suicida se quita la vida porque entiende que no tiene sentido si no puede seguir sirviendo a la institución a la que se había entregado (recordemos los ejemplos: el matrimonio, el ejército). Por contra, las sociedades poco integradas (laicas, individualistas) se asocian con un tipo de suicidio "egoísta» (el clásico de las personas depresivas que no hallan amparo en ningún manto protector), propio de países protestantes y/o desarrollados.

Si la variable integración se antoja diacrónica, la variable complementaria - organización - parece aludir a características sincrónicas o atemporales, aunque Durkheim se refiriera a su época como un período de fuerte déficit organizativo. En particular el autor alude al mayor o menor grado de éxito en la coordinación estructural de sus recursos y normas de funcionamiento que una sociedad pueda desarrollar. Una sociedad muy organizada podrá caer en el extremo del «fatalismo», desencadenando entre sus integrantes una opresión visualizada en un tipo de suicidio («fatalista») que Durkheim consideraba históricamente residual e hipotético (pone el ejemplo de sociedades archiesclavistas en las que se suicidarían los mismos esclavos sometidos a un trato insoportable). Por su parte, las sociedades desorganizadas entran en el extremo de la «anomia», o ausencia de normas estructuradas, dando lugar a conductas suicidas —el «suicidio anómico»— como las de los empresarios arruinados a su pesar (por culpa de una economía que no sabe estabilizarse) y a conductas parasuicidas como las de los delincuentes y marginales más temerarios y agresivos. Con el concepto de anomia Durkheim inauguraba una riquísima línea de análisis de la desviación y las fracturas sociales que supieron desarrollar la Escuela de Chicago y Merton y que sigue mostrando su fecundidad en nuestros días, como ha puesto de manifiesto Dahrendorf ${ }^{2}$.

El cruce entre las variables integración y organización continúa siendo una vía de análisis para los procesos de cambio social interesante aún hoy en día. Puede darse la paradoja de que haya sociedades muy integradas y poco organizadas o viceversa; lo mismo que sociedades con dosis razonables y simultá-

1. Castilla del Pino, Carlos (1969). Un estudio sobre la depresión. Barcelona: Península, p. 245.

2. Dahrendorf, Ralf (1988). The modern social conflict. Londres: Weindenfeld and Nicolson, p. 158 y siguientes. 
neas de ambas variables, o, lo que es peor, con muy bajas dosis de las dos. Piénsese en países como España, dotado de un más que considerable grado de consenso valorativo en torno a los principios democráticos y constitucionales, pero con dificultades en los que concierne a la superación de problemas estructurales como el desempleo. Algo similar podríamos decir de sociedades del presente como las latinoamericanas o las de la Europa del Este. En sentido inverso, hay países dictatoriales como China en los que la alta dosis organizativa no se compadece con su pobre clima de integración cívico-moral. En fin, podríamos traer a colación también situaciones de quiebra integradora y organizativa (Bosnia, Albania, Argelia), cuyo polo opuesto lo constituyen sociedades que puntúan alto con respecto a ambos tipos de variables (países escandinavos, por ejemplo). Quizá resulte útil traducir a un cuadro las posibilidades ilustradoras que se esconden tras la propuesta de Durkheim:

\begin{tabular}{|c|c|c|}
\hline & \multicolumn{2}{|l|}{ ORGANIZACIÓN } \\
\hline INTEGRACIÓN & + & - \\
\hline \multirow[t]{2}{*}{+} & $\begin{array}{l}\text { Sociedades democráticas } \\
\text { desarrolladas. }\end{array}$ & $\begin{array}{l}\text { Sociedades en crisis de } \\
\text { crecimiento. }\end{array}$ \\
\hline & Sociedades tradicionales. & \\
\hline- & $\begin{array}{l}\text { Sociedades dictatoriales } \\
\text { modernizantes. }\end{array}$ & $\begin{array}{l}\text { Sociedades en trance de } \\
\text { disolución (guerra civil; } \\
\text { revolución continuada). }\end{array}$ \\
\hline
\end{tabular}

Según este cuadro, las sociedades, bien antiguas y tradicionales, bien democráticas y desarrolladas, compartirían altos grados de integración y organización: las primeras, al descansar en sistemas valorativos incuestionados y en marcos organizativos rudimentarios y de poco ámbito territorial que aseguran la eficacia normativa; las segundas, por aunar esta última eficacia (tecnoburocrática) con una elevada conciencia cívica.

En cuanto al déficit organizativo unido a un razonable consenso cívicomoral, sería una circunstancia típica de países que tienen claras sus metas pero no tanto los recursos necesarios para llegar a ellas (así, el área latino-americana que veíamos antes). Son las que denomino «sociedades en crisis de crecimiento».

La celdilla inferior izquierda resumiría la situación por la que atraviesan las sociedades (Alemania bismarckiana, España franquista, China contemporánea, por ejemplo) que experimentan períodos de modernización autoritaria.

Por fin, la confluencia de mínimos integradores y organizativos distinguiría a países en épocas de conflicto social o político abierto.

Si nos hemos detenido hasta ahora en los aspectos más positivos y permanentes de El suicidio, ello no quiere decir por supuesto que la obra no eviden- 
cie el paso de los años y deje de estar supeditada al clima intelectual de la época. Naturalmente que esto último es cierto. No obstante, es el estilo y la intencionalidad última del clásico de Durkheim lo que mantiene incólume su brillo.

Entre los "puntos negros» del estudio se cuenta muy prioritariamente el acusado patriarcalismo de que hacen gala los análisis durkheimianos. El autor pensaba que uno de los síntomas de anomia es la proliferación de divorcios, para añadir a continuación que el hecho de que fueran más abundantes los suicidios de varones divorciados que el de mujeres en idéntico estado civil se debía a una especie de carácter innatamente «salvaje» de las mujeres. Por eso llegó a recomendar, más allá de las dificultades que pudieran atravesar, para salvaguardar la salud pública ${ }^{3}$. No hay nadie a estas alturas que tenga empacho en reconocer que Durkheim, al interpretar los datos a su alcance, se dejó guiar por prejuicios. Sin embargo, no es menos cierto que la investigación reciente continúa detectando una suerte de «inmunidad» de las casadas y divorciadas frente al suicidio ${ }^{4}$.

También es verdad que el instrumental estadístico manejado por el autor podría haberse refinado algo más, aunque del mismo modo hay unanimidad en reconocer a Durkheim un papel precursor en el uso de las técnicas de correlación 5 .

Igualmente, resulta sorprendente que El suicidio eluda una variable tan significativa como la edad, según ha tenido oportunidad de poner de manifiesto recientemente un compatriota de Durkheim (quien descubre que no todas las cohortes de edad siguen las conductas suicidas de la manera sugerida por nuestro autor) $)^{6}$.

Pero lo más frustrante del libro es el desprecio total que Durkheim siente por el suicidio fatalista, el cual, según advertía anteriormente, queda relegado a la categoría de pura hipótesis lógica, y sin apoyatura histórica, en forma de nota a pie de página. ¿Por qué esta renuncia a cerrar el «rectángulo» de suicidios arquetípicos (que, por cierto, hubiera permitido establecer una tipología aún más compleja que la que el autor propone al final del libro II, delimitando en ella "tipos elementales» $y$ «mixtos» de suicidio)?

Es difícil responder a la pregunta. Una respuesta apegada a la literalidad durkheimiana es que, en efecto, salvo casos límite como el de Esparta (el de los campos de concentración que el autor, afortunadamente para él, no conoció), no existen situaciones sociales con un índice de organización tan elevado que «aplaste» hasta el suicidio a algunos de sus integrantes. Philippe Besnard

3. Véase Ramos, Ramón (1996). «Los saberes del patriarca». En DurÁN, Ma Ángeles (comp.). Mujeres y hombres en la formación de la teoría sociológica. Madrid: Centro de Investigaciones Sociológicas; ídem (1998). "Un tótem frágil» y "Antes y después de El suicidio». Revista Española de Investigaciones Sociológicas, 81.

4. Véase Besnard, Philippe (1997). "Mariage et suicide». Révue Française de Sociologie, XXXVIII-4.

5. Véase Alvira, Francisco; Blanco, Francisca (1998). «Estrategia y técnicas investigadoras en el El suicidio». Revista Española de Investigaciones Sociológicas, 81.

6. Véase Chauvel, Louis (1997). "Âge et suicide». Révue Française de Sociologie, XXXVIII-4. 
sugiere, a cambio, una interpretación más aguda: Durkheim habría descubierto los polos de una dimensión organizativa que el citado autor denomina «regulación», pero no fue capaz de utilizarla como escala en sus análisis explicativos de la conducta suicida porque se dejó llevar en exceso, en sus consideraciones sobre la anomia, de valoraciones extrasociológicas (así, las diferencias entre el apetito sexual masculino y femenino en el seno del matrimonio) que obligaban a circunscribir la utilización de la escala a uno de sus extremos -el anómico ${ }^{7}$.

Ahora bien, precisamente porque El suicidio continúa motivando relecturas y mejoras de su aparato de hipótesis explicativas, nos encontramos ante un clásico de verdad. No ante un libro que despierte veneración y quede intacto, sino ante una mirada y práctica sociológicas cargadas de acierto y contenido que invitan a su incesante recuerdo y superación.

Honra a Papers que haya querido destacar como se merece el centenario de esta pieza decisiva en la historia de la teoría sociológica y yo personalmente me siento muy orgulloso de contribuir mínimamente a la conmemoración. No es la única revista de nuestro entorno que lo ha hecho (también le han dedicado volúmenes conmemorativos la Revista Española de Investigaciones Sociológicas y la Révue Française de Sociologie $\left.{ }^{8}\right)$. Todo eso y mucho más es lo que demanda el esfuerzo ejemplar que un día acometiera el maestro francés.

7. Besnard, Philippe (1998). "Anomia y fatalismo en la teoría dukheimiana de la regulación». Revista Española de Investigaciones Sociológicas, 81.

8. Véanse los números de ambas revistas profusamente citados en esta nota. Es curioso que la revista española se ha centrado abundantemente en la obra y época de Durkheim, mientras que la francesa se haya situado sencillamente a su sombra, convirtiendo la conmemoración en una puesta a prueba del alcance de las hipótesis durkheimianas a lo largo de un par de artículos de investigación estadística. 